\title{
Bog breathing: the extent of peat shrinkage and expansion on blanket bogs in relation to water table, heather management and dominant vegetation and its implications for carbon stock assessments
}

\author{
Phoebe A. Morton $(\mathbb{D} \cdot$ Andreas Heinemeyer $(\mathbb{D}$
}

Received: 19 February 2019/Accepted: 23 May 2019/Published online: 3 June 2019

(C) The Author(s) 2019

\begin{abstract}
Peatlands represent a globally important carbon stock. Peat soil carbon stock assessments rely on measurements of carbon concentration, bulk density and soil depth. However, peat surface levels - and thus soil depths - change ("bog breathing") largely as a response to peat shrinkage and expansion in relation to water table changes. This study assessed the magnitude of and potential for this mechanism to influence carbon stock calculations under field and laboratory conditions. In the UK, most peatlands are upland blanket bogs, of which a large proportion are managed as 'grouse moors'. This currently involves rotational burning, although alternative management is increasingly considered. Peat depth and water tables were investigated on three grouse moors on blanket bog in northern England, comparing changes under different heather management interventions (burning, mowing and uncut). One site also allowed investigation of changes in relation to slope and under the three major bog vegetation types (ling heather, cottongrass and Sphagnum moss), which were
\end{abstract}

P. A. Morton · A. Heinemeyer ( $\square)$

Department of Environment \& Geography, Stockholm

Environment Institute, University of York,

York YO10 5NG, UK

e-mail: andreas.heinemeyer@york.ac.uk

Present Address:

P. A. Morton

Agri-Food and Biosciences Institute, 18a Newforge Lane,

Belfast BT9 5PX, UK compared to observed changes in peat cores under controlled laboratory conditions simulating periods of drought and rewetting. Changes in depth and bulk density were recorded and the potential implications for carbon stock estimates were calculated. Results highlight site specific relationships as potential habitat condition indicators and demonstrate that previously reported surface peat carbon losses resulting from enhanced decomposition under rising temperatures might also be explained by apparent changes due to peat shrinkage and expansion. It is recommended to accurately record bulk density and total peat depth measurements as part of peat carbon stock assessments.

Keywords Bulk density · Peatlands · Peat shrinkage and expansion - Calluna vulgaris - Sphagnum .

Eriophorum

\section{Introduction}

Globally, peatlands contain $\sim 30 \%$ of all soil organic carbon (SOC), despite covering only $3 \%$ of the land surface (Parish et al. 2008). In the northern hemisphere circumpolar region, it is the generally low temperatures, high or shallow water table depth (WTD; henceforth a higher water table is less negative and thus means wetter conditions with zero at the peat 
surface), high peat moisture, and the resulting slow decay rates of soil organic matter (SOM) that allow peat to form. Blanket bogs are a globally rare peatland habitat with the UK accounting for about $15 \%$ of the global total (Tallis 1998). In the UK, about $95 \%$ by area of all peatlands are blanket or raised bogs (Bain et al. 2011), of which around $30 \%$ are subjected to rotational burning (Natural England 2010), commonly supported by draining of peat, to encourage increased abundance of ling heather (Calluna vulgaris) for grouse shooting. Burning on blanket bogs has been highlighted as having negative impacts on many of the peatland ecosystem services such as biodiversity, water storage, high quality drinking water provision, flood prevention and carbon (C) storage (Evans et al. 2014). Reflecting this, there is a commitment to phaseout routine, rotational burning on blanket peat in England (Natural England 2015), though burning may continue to be used as a tool under restoration and wildfire risk management plans, in particular to address over-dominance of heather. Therefore, exploring alternative heather management options such as mowing (see Heinemeyer et al. 2019) is of key importance in relation to assessing the impacts of management and climate on long-term peat $\mathrm{C}$ accumulation and storage in blanket bogs.

Measurements of $\mathrm{C}$ stocks and their changes over time are limited to a few studies, particularly on peatlands. In the UK, Bellamy et al. (2005) found that English and Welsh soils with organic $\mathrm{C}$ contents $\left(\mathrm{C}_{\text {org }}\right)$ higher than $50 \mathrm{~g} \mathrm{~kg}^{-1}$ lost $\mathrm{C}$ in soil samples taken between 1978 and 2003 and that the rate of loss increased with increasing $\% \mathrm{C}_{\mathrm{org}}$, and hence was particularly high on blanket bogs. However, peat $\mathrm{C}$ stock density assessments rely on accurate assessment of the amount of SOM and its C content as well as bulk density (BD) over a defined soil depth. Importantly, as in blanket bogs $\mathrm{BD}$ values are generally very low (around $0.1 \mathrm{~g} \mathrm{~cm}^{-3}$; see Heinemeyer et al. 2010), inaccuracies in $\mathrm{BD}$ values can have considerable consequences for $\mathrm{C}$ stock density estimates.

Peat surface level fluctuations due to changes in WTD or pressure are well known (Strack et al. 2006). They are sometimes referred to as "bog breathing" (Ingram 1983) and have been proposed as a peatland habitat monitoring tool (Stoneman and Brooks 1997). However, little is known about how this fluctuation is affected by different vegetation types, although Howie and Hebda (2018) recently explored this on a
Canadian raised bog, and whether these level changing processes cause irreversible changes in the peat that might prevent it recovering to a previous or 'natural' level after periods of drought. Moreover, so far it is unknown how changes in peat surface levels affect $\mathrm{BD}$, particularly on blanket bogs. Importantly, as the most severe BD changes are likely to occur at the peat surface (where the greatest changes in soil moisture occur), such changes could significantly affect peat $\mathrm{C}$ stock calculations that focus on the surface layers. For example, Bellamy et al. (2005) only sampled the top $15 \mathrm{~cm}$ of soil, BD values were not measured (but instead derived from a generic equation) and samples were unlikely to have all been taken at the same time of year or under similar environmental conditions. Therefore, if soil moisture was lower and hence BD and $\mathrm{C}_{\text {org }}$ density were greater in the first sampling period, a wetter second sampling period could have resulted in the appearance of reduction in soil $\mathrm{C}_{\text {org }}$ stocks over the same surface layer thickness. Additionally, vegetation type likely alters peat structure and possibly also $\mathrm{BD}$, and vegetation composition of the areas sampled may have been different.

This study measured, for the first time, peat surface fluctuations on blanket bogs under different vegetation types, management interventions and WTDs, and also evaluated the extent to which this physical impact could influence $\mathrm{C}$ stock inventories and changes, such as those reported by Bellamy et al. (2005) for highly organic soils. A combined approach of controlled laboratory experiments and field monitoring assessed two hypotheses:

(1) a calculated 'apparent' change in $\mathrm{C}_{\text {org }}$ densities can be explained by peat surface fluctuations (i.e. change in total peat depth), which cause significant changes in BD in the surface peat without any 'real' changes in $\mathrm{C}_{\text {org }}$ occurring, and

(2) these peat surface and BD fluctuations can be affected by land management, vegetation type and WTD.

\section{Methods}

Glasshouse cores

Peat cores of $1 \mathrm{~m}$ length were obtained using a $5 \mathrm{~cm} \times 5 \mathrm{~cm}$ box corer on 20th November 2013 from a flat (slope of $<5^{\circ}$ ) area of blanket bog at Mossdale 
in Upper Wensleydale within the Yorkshire Dales National Park, UK (at $54^{\circ} 19^{\prime} 01^{\prime \prime} \mathrm{N} ; 2^{\circ} 17^{\prime} 18^{\prime \prime} \mathrm{W}$ ) about 390 m a.s.l. (see Fig. 1a and Heinemeyer et al. (2019) for further detail on vegetation and site history). In total, 24 cores were removed; eight each from areas dominated by Sphagnum (moss) species, Eriophorum (cottongrass) species or Calluna vulgaris (ling heather). Cores were cut into $15-20 \mathrm{~cm}$ sections to avoid excess compression on removal from the auger. Each core was reassembled in a $1 \mathrm{~m}$ long, square uPVC plastic conduit $(5 \mathrm{~cm} \times 5 \mathrm{~cm})$ with a detachable cover (Edmundson Electrical Ltd, York, UK). Care was taken to place the deepest part of the core at the end of the ducting pipe to minimise slippage when the pipe was stood upright. Further, a uPVC end cap was fitted to the end of each pipe, once the detachable

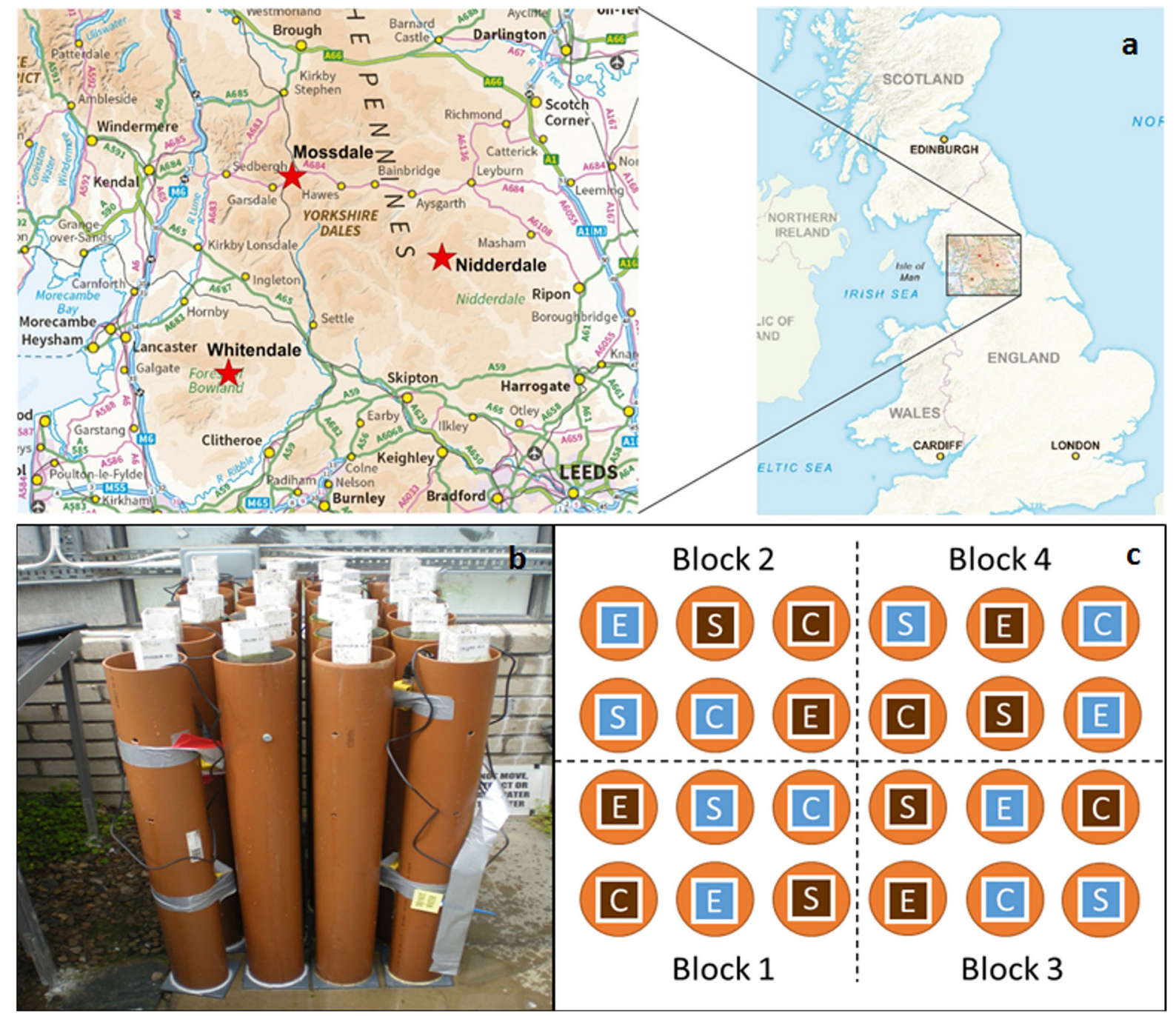

Fig. 1 Field sites and experimental setup. Shown are a the locations in northern England (inset) in relation to the United Kingdom (outline) for the three sites Nidderdale, Mossdale and Whitendale (indicated by the red stars), b photo of the glasshouse setup with the 24 peat cores, with stoppers either removed or left in place to regulate water levels to $0 \mathrm{~cm}$, $-15 \mathrm{~cm},-35 \mathrm{~cm}$ or $-100 \mathrm{~cm}$ clearly visible in the front of the outer orange uPVC tubes, and c schematic of the glasshouse setup with the 24 peat cores, with each core inside white square tubing which is inside an orange UPVC tube with drainage holes, where dark brown cores are in Set1 (WTD started at $0 \mathrm{~cm}$ ) and blue cores are Set 2 (WTD started at $-35 \mathrm{~cm}$ ), C cores were Calluna-topped, E cores were Eriophorum-topped and S cores were Sphagnum-topped. Maps downloaded: 9th September 2016 from MiniScale ${ }^{\circledR}$ [TIFF geospatial data] during download of GB tiles (updated 3rd December 2015) from Ordnance Survey (GB) using the EDINA Digimap Ordnance Survey Service (http://digimap.edina.ac.uk) 
side had been replaced, to prevent slippage and peat loss at the bottom of the tube. The end cap was not sealed on in order to enable drainage and water movement throughout the cores.

Cores were transported to an unheated glasshouse and stood upright in a minimum of $30 \mathrm{~cm}$ of water. On 25th November 2013, the ducting pipes containing the cores were individually and randomly placed into larger tubes consisting of a $95 \mathrm{~cm}$ long, $11 \mathrm{~cm}$ diameter uPVC tube (Plumb Center, Wolseley UK Ltd, Leamington Spa, UK) glued into an indentation on a $12 \mathrm{~cm}$ square of PVC (Biology Workshops, University of York, UK). Tube bases were sealed to make them watertight. A $1 \mathrm{~cm}$ diameter drainage hole was drilled through each tube $15 \mathrm{~cm}$ from the top. Half of the tubes had an additional hole drilled through them $35 \mathrm{~cm}$ from the top, into which a removable watertight bung was fitted. All tubes were filled with water up to the $15 \mathrm{~cm}$ hole (see Fig. $1 \mathrm{~b}$ for a picture of the tube setup).

On 11th December 2013, four evenly-spaced $0.6 \mathrm{~mm}$ diameter holes were drilled along the detachable side of each square pipe to aid drainage and water movement. Additionally, the top 4-5 cm of each core was sliced off to remove the surface vegetation and parts of the top root layer to provide a definitive peat surface. As this lowered the peat surface relative to the holes in the outer tubes, the removal of the top of each core raised the WTD to $-15 \mathrm{~cm}$ (i.e. $15 \mathrm{~cm}$ below the peat surface). Four cores had resettled such that there was a gap between the bottom of the core and the end cap. A small piece $(<1.5 \mathrm{~cm})$ which had been removed from the top of these cores was added to the bottom to prevent sudden slippage later which may have impacted the measurements. The distance from the centre of the peat surface (i.e. where the vegetation was removed) to the top of the ducting tube was measured to the nearest millimetre and subtracted from the height of the ducting pipe. This was taken to be the starting height of each peat core.

On 22nd January 2014, the cores were assigned to one of four blocks, such that each block contained two Calluna- (C), two Eriophorum- (E) and two Sphagnum- (S) topped cores (Fig. 1c). Cores were arranged within blocks according to a Latin square, with one core of each species in a tube with two holes and one in a tube with one hole (Fig. 1c). The distance from the peat surface to the top of the ducting pipe was measured approximately $0.5 \mathrm{~cm}$ from each of the four corners of each core using a pair of callipers (Traceable Digital Carbon Fiber Calipers, Fisher Scientific, Pittsburgh, PA; accuracy $\pm 0.2 \mathrm{~mm}$ ) and subtracted from the height of the pipe $(1 \mathrm{~m})$ to obtain the height of the peat core. Water was added to tubes at least weekly so that the WTD never dropped more than $2 \mathrm{~cm}$ below the desired level. All cores were measured six times over the 4 month time period (TP) with WTD maintained at $-15 \mathrm{~cm}$. This was TP1.

On 17th April 2014, bungs were rearranged such that the WTD of the single-holed tubes was raised to $0 \mathrm{~cm}$ (Set1) and that of the two-holed tubes was lowered to $-35 \mathrm{~cm}$ (Set2). Due to the top of all cores being below the top of the piping tubes, the piping tubes being $5 \mathrm{~cm}$ taller than the outer tubes, and the surface fluctuations of the cores themselves, these WTDs are the highest that the peat cores experienced. Therefore, the WTDs experienced by the cores were between $-5 \mathrm{~cm}$ and $0 \mathrm{~cm}$ for the wetter tubes and $-40 \mathrm{~cm}$ and $-35 \mathrm{~cm}$ for the drier tubes. Cores were measured by the same calliper method 11 times over 9 months, with intervals between measurements ranging from 1 to 11 weeks. This was TP2.

To test whether cores which had been under a specific WTD long-term would behave similarly when placed under the other WTD, cores were swapped pairwise by species within blocks (e.g. the WTD of both Calluna-topped cores within block 1 was swapped) on 21st January 2015. Cores were then measured seven times over 5 months as previously. This was TP3.

On 24th June 2015, all bungs were replaced and the WTD was raised to $0 \mathrm{~cm}$ for all tubes to investigate whether all cores would recover (i.e. return to their original height) and rehydrate fully. Cores were measured six times over 3 months. This was TP4.

Finally, on 2nd October, all tubes were fully drained to simulate a WTD of $-100 \mathrm{~cm}$ and left for a month for the peat to drain. After a month, the cores were measured twice in the following month to obtain an indication of maximum shrinkage potential. This was TP5.

Glasshouse core bulk densities (BDs)

As well as the WTDs of the cores being switched on 21st January 2015 (after the first wet/dry set period, i.e. start of TP3), the top 4-5 cm of all cores from three blocks (i.e. three individual replicates of each 
vegetation type and Set) were removed with a sharp knife. These removed cuboids were measured in all three dimensions with callipers and oven-dried at $105^{\circ} \mathrm{C}$ in foil dishes until a constant weight was achieved (2-3 days). The BD was calculated by dividing the final dry weight by the volume, derived from the three side measurements.

\section{Field poles}

To verify the peat surface fluctuations of the glasshouse cores, $12 \mathrm{~mm}$ solid steel rod poles (Blacker Steel Ltd., York) were installed in the field. All poles were at least $40 \mathrm{~cm}$ longer than the peat depth at their respective installation locations. A $1 \mathrm{~mm}$ groove was marked $20 \mathrm{~cm}$ from the top of each pole around the circumference. Poles were pushed vertically into the peat until they reached the mineral substrate and then hammered about $20 \mathrm{~cm}$ into the underlying mineral layer (mainly composed of clay overlying sandstone and mudstone) with an iron mallet to prevent movement of the pole from frost heave or animal collision.

A custom-made coloured acrylic disc of $50 \mathrm{~mm}$ diameter and $2 \mathrm{~mm}$ thickness with an internal open circle of $15 \mathrm{~mm}$ (Biology Workshops, University of York, UK) was placed over each pole at ground level. The vegetation (litter and moss cover) beneath each disc was cleared away such that the discs could lie flat on the peat surface and move freely. The discs were used to protect the peat surface and provide a solid reference point, even when vegetation grew back around the disc.

A pole was installed on each permanent monitoring plot, within $50 \mathrm{~cm}$ of a dipwell, at each of the three blanket bog sites (Nidderdale: $54^{\circ} 10^{\prime} 07^{\prime \prime} \mathrm{N}$; $1^{\circ} 55^{\prime} 02^{\prime \prime} \mathrm{W}$, Mossdale: $54^{\circ} 19^{\prime} 01^{\prime \prime} \mathrm{N} ; 2^{\circ} 17^{\prime} 18^{\prime \prime} \mathrm{W}$ and Whitendale: $53^{\circ} 59^{\prime} 04^{\prime \prime} \mathrm{N} ; 2^{\circ} 30^{\prime} 03^{\prime \prime} \mathrm{W}$ ) of a long-term field experiment in northern England (see Fig. 1a and Heinemeyer et al. 2019 for details and descriptions of sites and plots). Briefly, all sites were blanket bog with a peat depth of $1.5 \mathrm{~m}$ ( $\pm 0.4 \mathrm{~m}$ standard deviation), largely dominated by Calluna vulgaris and under rotational heather burning management on a 10-15 year cycle. However, Nidderdale had low Sphagnum cover, whereas Whitendale and Mossdale were more Sphagnum rich, reflecting their monthly average ( \pm standard deviation) WTDs: Nidderdale $(-14.6 \pm 6.4 \mathrm{~cm})$ was driest, with Whitendale $(-8.7 \pm 6.9 \mathrm{~cm})$ and Mossdale $(-8.1 \pm 5.7 \mathrm{~cm})$ wetter. This was based on measured daily WTD (Omnilog, WT-HR 1000, TruTrack, New Zealand) on uncut heather-dominated plots $(\mathrm{n}=4$ per site) during 2012-2016 (see Heinemeyer et al. 2019). The plots were either recently (spring 2013) burnt (FI), mown with the brash left (LB), mown with the brash removed (BR) or were left unmanaged as "do nothing" uncut plots dominated by mature Calluna (DN). There were four FI and DN plots per site and eight BR and LB plots. These poles were inserted at Nidderdale and Mossdale on 4th August 2014 and at Whitendale on 5th August 2014.

A further 90 poles were installed at Mossdale in clusters of three on 5th and 7th August 2014. Within a group, poles were between $0.5 \mathrm{~m}$ and $1 \mathrm{~m}$ apart. In the centre of each cluster, a $1 \mathrm{~m}$ long core which was $5 \mathrm{~cm} \times 5 \mathrm{~cm}$ square was removed (see box corer description above). This hole was used as a dipwell to measure the WTD. Six clusters of three poles were installed on areas dominated (i.e. the vegetation all three poles were in was over $70 \%$ of that species) by Sphagnum species (largely S. capillifolium and $S$. fallax), six on areas dominated by Eriophorum, six by mature Calluna, six on recently burnt Calluna and six on recently mown Calluna. If any, then there were only limited fragments of Sphagnum moss on the Eriphorum and Calluna dominated plots. For each of these species/management groups, three clusters were located on a shallow slope $\left(\leq 5^{\circ}\right)$ and three on a steeper slope $\left(>5^{\circ}\right)$.

Peat depth of all locations was measured and recorded prior to pole installation. The distance between the top of the pole and the disc on the peat surface was measured when poles were installed and a further seven times over the following 2 years (until December 2015). Measurement error was determined as less than $1 \mathrm{~mm}$ by repeated measurements at the same location. At the same time, the WTD was measured manually both on the plots and in the central holes of the groups of three. The distance from the top of the pole to the $20 \mathrm{~cm}$ groove was also measured to check whether the pole itself had expanded or contracted due to temperature (but no change was detected). Moreover, the poles on the management plots were measured at all three sites twice more, once in mid-March 2016, and once on 16th July 2018 after a prolonged summer drought with extremely low WTDs. 
Data analysis

All statistical analyses were carried out in $\mathrm{R}$ version 3.3.1 (R Core Team 2016). Where values are quoted, these represent the mean $( \pm 95 \%$ confidence intervals), unless otherwise stated. The critical $p$ value chosen for significance was 0.05 .

\section{Glasshouse cores}

The four measured peat heights for each core on each measurement occasion were averaged. The starting height of each core was subtracted from these peat heights to obtain the change in height for each measurement occasion. A three-way ANOVA was used to determine whether the change in peat height differed between vegetation type, Sets (and thereby by WTD) and TPs. Only the final set of measurements within each TP was used as these represented the maximum change in peat height for each core within each TP. Where significant differences were detected, the "TukeyHSD" function was used to determine between which groups significant differences occurred.

Glasshouse core bulk densities (BDs)

A two-way ANOVA, employing the "aov" function in the "stats" package (R Core Team 2016), was used to investigate the effects of vegetation type and WTD on BD. Where significant differences were detected, the "TukeyHSD" function was used to determine between which groups significant differences occurred. A Shapiro-Wilk test ("shapiro.test" from the "stats" package; R Core Team 2016) was used to test whether the residuals followed a normal distribution and Levene's test ("leveneTest" from the "car" package; Fox and Weisberg 2011) was used to assess homogeneity of variance.

Field poles

Change in peat depth was calculated as the total pole length minus the distance from the disc on the peat surface minus the length of pole in the bedrock (initially calculated based on the pole length, starting peat depth and starting length of pole protruding from the peat). Similarly, change in WTD was calculated by subtracting the WTD on each measurement date from the WTD when the poles were installed.

The poles which had been installed on the permanent plots across the three sites ("plot data") were analysed separately from the additional 90 poles installed at Mossdale ("+ 90 data"). Linear mixed effects models employing the "lmer" function from the "ImerTest" package (Kuznetsova et al. 2016) were used to test which factors affected the change in peat height. For the plot data, management, site and change in WTD were used as fixed effects, as were the interactions between them, and a random intercept was included with a nested structure of blocks in sites (to account for spatial heterogeneity) in measurement dates (to account for repeated measurements). For the +90 data, vegetation type, slope category (shallow or steep), change in WTD and the interaction between them were used as fixed effects, with pole cluster nested in measurement date as the random intercept.

Following the 10-step protocol in Sect. 5.10 of Zuur et al. (2009), variables were dropped stepwise from each linear mixed effects model and the loglikelihood ratio and AIC value were used to assess whether a variable should be dropped or kept in the model. For the final models, the "satterthwaite" option was used to calculate the denominator degrees of freedom as the missing heights of three poles during one measurement date for the +90 data, and the number of plots under each management within the plot data, resulted in an unbalanced design (Spilke et al. 2005). Where significant interactions were found, the "glht" function with the "Tukey" option from the "multcomp" package (Hothorn et al. 2008) was used to compare groups within the interaction terms.

Microsoft Excel (v. 14) was used to identify a bestfit regression equation for the 2018 peat depth versus WTD changes in relation to site.

\section{Results}

Glasshouse cores

The relative change in peat height of the glasshouse cores over the experimental period, compared to their starting height, ranged from $-3.67 \%$ to $1.29 \%$ (Fig. 2) corresponding to an absolute change of $-3.48 \mathrm{~cm}$ to $1.22 \mathrm{~cm}$ with a mean of $-0.67 \mathrm{~cm}$. 


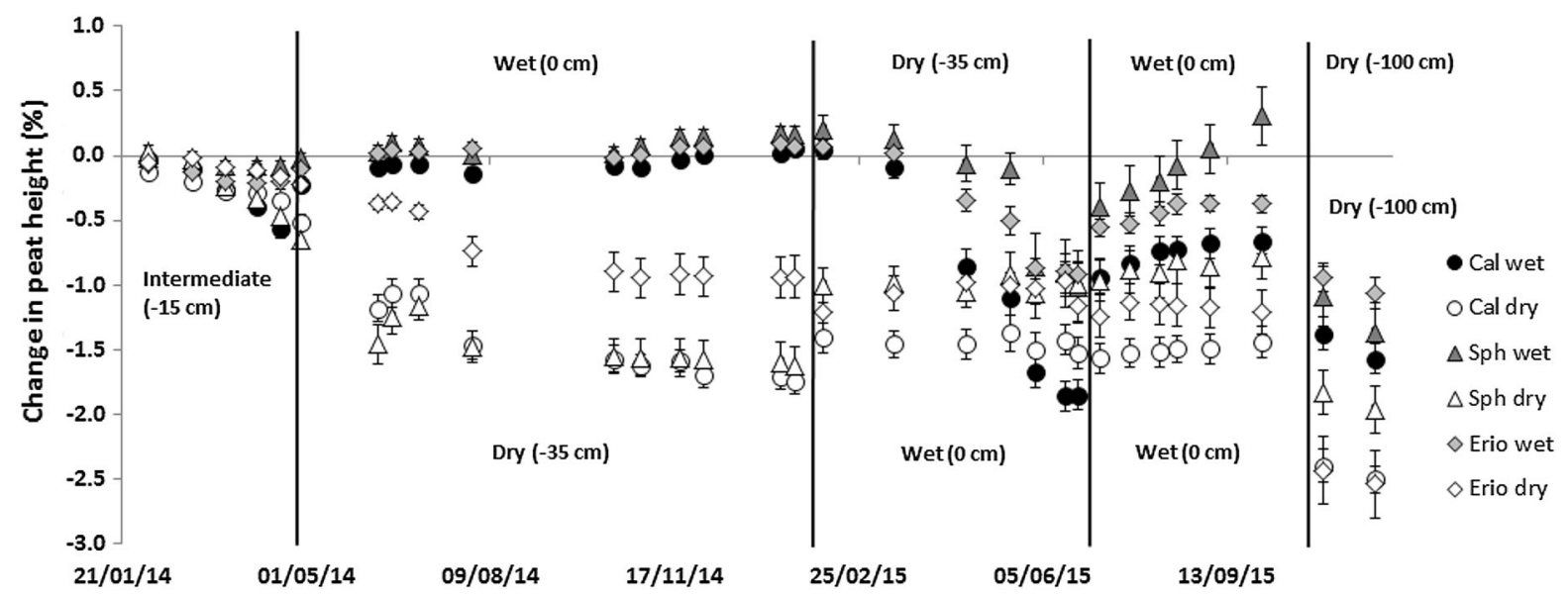

Fig. 2 Average relative ( $\% \pm$ standard error) shrinkage and expansion (compared to the initial peat surface) of the glasshouse peat cores under various water table depth (WTD) as indicated on the graph (cores were initially at $-15 \mathrm{~cm}$, then one half was wet $(0 \mathrm{~cm})$, the other dry $(-35 \mathrm{~cm})$, then treatment was switched, then all were wet and then all were very dry $(-100 \mathrm{~cm}))$. Infilled shapes track the rise and fall of the peat surface for cores which were allocated to the wet $(0 \mathrm{~cm})$

treatment immediately following the initial intermediate period $(-15 \mathrm{~cm})$ and open shapes track surface fluctuations of cores allocated to the dry treatment $(-35 \mathrm{~cm})$ during the same period. Times where WTDs were changed (TPs) are indicated by vertical black lines. Different shapes indicate the different peat cores under predominantly Calluna (Cal), Sphagnum (Sph) or Eriophorum (Erio) surface cover

Across all TPs, the greatest range of vertical movement in a single core was $3.57 \mathrm{~cm}$ and the smallest was $0.78 \mathrm{~cm}$ (both were Eriophorum-topped cores), with a mean of $1.99 \mathrm{~cm}$ across all cores. The greatest mean absolute shrinkage in a treatment period compared to the height at the start of the experiment was observed for Set2 in TP5 with $-2.23 \mathrm{~cm}$ (Fig. 3).

The change in the height of the peat cores differed significantly between the three vegetation types $\left(\mathrm{F}_{2,90}=8.26, \mathrm{p}=0.0005\right)$, with Calluna-topped cores shrinking more on average than Sphagnum- or Eriophorum-topped cores $(\mathrm{p}<0.0003)$. However, there was no interaction between vegetation types and TPs $\left(\mathrm{F}_{8,90}=0.92 \mathrm{p}=0.50\right)$ or between Sets, vegetation types and TPs $\left(\mathrm{F}_{8,90}=0.90, \mathrm{p}=0.52\right)$. The change in

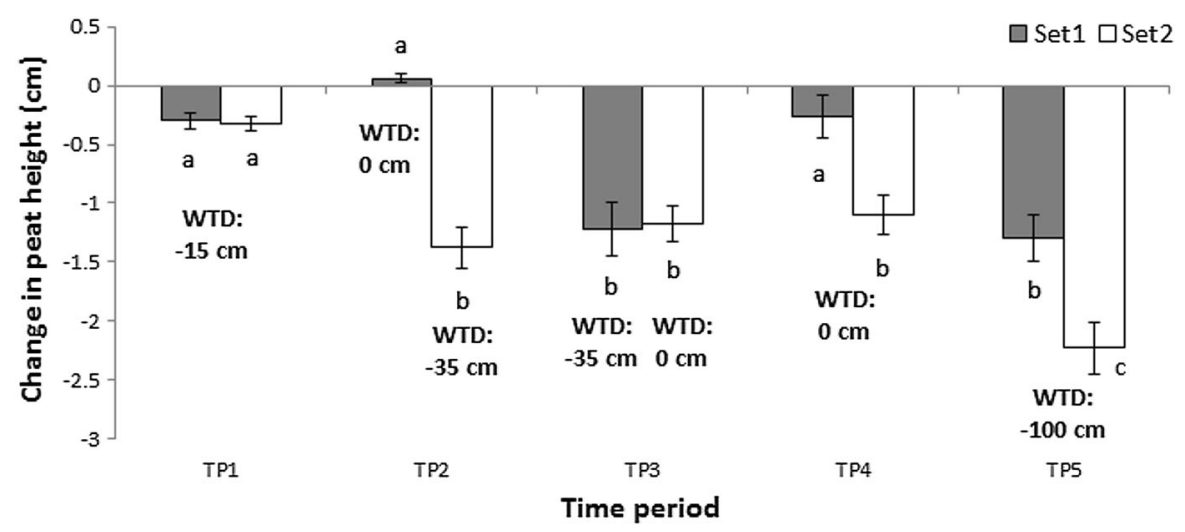

Fig. 3 Average absolute ( $\mathrm{cm} \pm$ standard error) shrinkage and expansion (compared to the initial peat surface) of the glasshouse peat cores under the five water table depth (WTD) periods: TP1 (all $-15 \mathrm{~cm}$ ), TP2 (half at either $0 \mathrm{~cm}$ or $-35 \mathrm{~cm}$ WTD), TP3 (switched wet and dry), then TP4 (all cores wet) and TP5 (all cores dry at $-100 \mathrm{~cm}$ WTD). Set1

includes all cores which were allocated to the wet $(0 \mathrm{~cm})$ treatment immediately following the initial intermediate period $(-15 \mathrm{~cm})$ regardless of vegetation type and Set2 shows the average surface fluctuations of cores allocated to the dry treatment $(-35 \mathrm{~cm})$ regardless of vegetation type. Significant differences (ANOVA) are shown by different letters 
the height of the peat cores differed significantly between the two Sets $\left(\mathrm{F}_{1,90}=42.48, \mathrm{p}<0.0001\right)$ and the five TPs $\left(\mathrm{F}_{4,90}=26.72, \mathrm{p}<0.0001\right)$, and there was a significant interaction between Sets and TPs $\left(\mathrm{F}_{4,90}=8.39, \mathrm{p}<0.0001 ;\right.$ Fig. 3).

On average, all cores lost about $0.3 \mathrm{~cm}$ during TP1, probably mainly due to settling of peat within the tubes, meaning that there was no difference between Sets $(p=1)$. The peat height diverged significantly in line with WTD during TP2 ( $<<0.0001)$ : Set1 cores, which had a high WTD of $0 \mathrm{~cm}$, regained the height lost during TP1 and gained another $0.1 \mathrm{~cm}$ whereas Set2 cores, which had a much lower WTD of $-35 \mathrm{~cm}$, lost nearly $1.4 \mathrm{~cm}$ on average. Interestingly, although the WTDs switched in TP3, causing Set1 to shrink, Set 2 regained very little height $(<0.2 \mathrm{~cm}$ on average) meaning that both Sets were very similar heights by the end of TP3 $(p=1)$ and suggesting that peat subject to low WTD for 9 months may shrink permanently. This idea was reinforced during TP4 when both Sets of cores were subject to higher WTDs $(0 \mathrm{~cm})$ but Set 2 again gained very little height. However, Set1 gained significantly more height than Set $2(p<0.009)$ and was not significantly shorter than during TP2 ( $\mathrm{p}=0.91)$ when the WTD was the same as TP4, suggesting that peat subject to a low WTD for 5 months or less can recover. When all cores were drained in TP5 (WTD - $100 \mathrm{~cm}$ ), on average all cores shrunk by over $1 \mathrm{~cm}$. However, as Set 2 cores had already lost more height than Set1 cores by the end of TP4, Set 2 cores were still significantly shorter at the end of TP5 $(\mathrm{p}<0.002)$.

Glasshouse core bulk densities (BDs)

BD ranged from 0.07 to $0.16 \mathrm{~g} \mathrm{~cm}^{-3}$ with a mean of $0.10 \mathrm{~g} \mathrm{~cm}^{-3}$ (Fig. 4). The BD of the glasshouse cores was slightly lower on average for the wetter cores $\left(0.10 \mathrm{~g} \mathrm{~cm}^{-3}\right)$ than the drier cores $\left(0.11 \mathrm{~g} \mathrm{~cm}^{-3}\right)$ but did not differ significantly between the two WTDs $\left(\mathrm{F}_{1,12}=3.04, \mathrm{p}=0.1069\right)$ nor between the three vegetation types $\left(\mathrm{F}_{2,12}=3.87, \mathrm{p}=0.0505\right)$ but there was a significant interaction between WTD and vegetation type $\left(\mathrm{F}_{2,12}=6.40, \mathrm{p}=0.0128\right)$. The Sphagnum-topped peat had a significantly higher BD when maintained at a deeper WTD $(-35 \mathrm{~cm})$ than when maintained at a WTD of $0 \mathrm{~cm}(\mathrm{p}=0.0452)$. The Sphagnum-topped peat with a WTD of $-35 \mathrm{~cm}$ also had a significantly higher BD than Eriophorum-topped

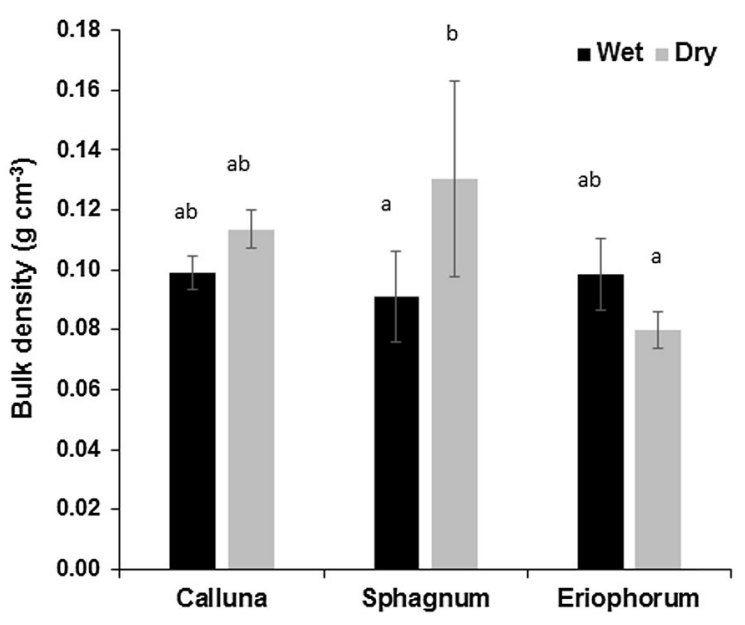

Fig. 4 Mean bulk densities ( $\pm 95 \%$ confidence interval) of the top $5 \mathrm{~cm}$ of peat for wet $(0 \mathrm{~cm}$ water table depth; WTD) and dry $(-35 \mathrm{~cm}$ WTD) cores after 9 months of constant WTD in the laboratory trial for the different vegetation groups (Calluna, Sphagnum or Eriophorum dominated surface vegetation cover). Significant differences (ANOVA) are indicated by different letters

peat with a WTD of $-35 \mathrm{~cm}(\mathrm{p}=0.0089)$. Interestingly, the dry Eriophorum-topped peat had the lowest BD of all the cores, although not significantly so.

Field poles

For the plot data, the greatest range of vertical movement in the peat height on a single plot was $1.9 \mathrm{~cm}$ at Nidderdale, $2.3 \mathrm{~cm}$ at Mossdale and $2.7 \mathrm{~cm}$ at Whitendale, with the smallest range being $0.4 \mathrm{~cm}$ at all sites. Overall, the average vertical movement in peat height for the plot data was $1.1 \mathrm{~cm}$ with a median of just under $1 \mathrm{~cm}$ (Fig. 5), which corresponded well to the observed values in the laboratory experiment (Fig. 3).

The amount of movement for the +90 data at Mossdale was similar, with the average range of the change in peat height being $1.3 \mathrm{~cm}$, the smallest range being $0.2 \mathrm{~cm}$ and the largest $3.1 \mathrm{~cm}$ across the different vegetation/management patches and slopes, with the median depth change being close to $0 \mathrm{~cm}$ (Fig. 6).

There was a significant effect of change in WTD on the change in peat height for both the plot data $\left(\mathrm{F}_{1,410}=23.36, \mathrm{p}<0.0001\right)$ and the +90 data $\left(\mathrm{F}_{1,168}=6.44, \mathrm{p}=0.0121\right)$, with an increase in peat height being related to shallower WTDs. The change 


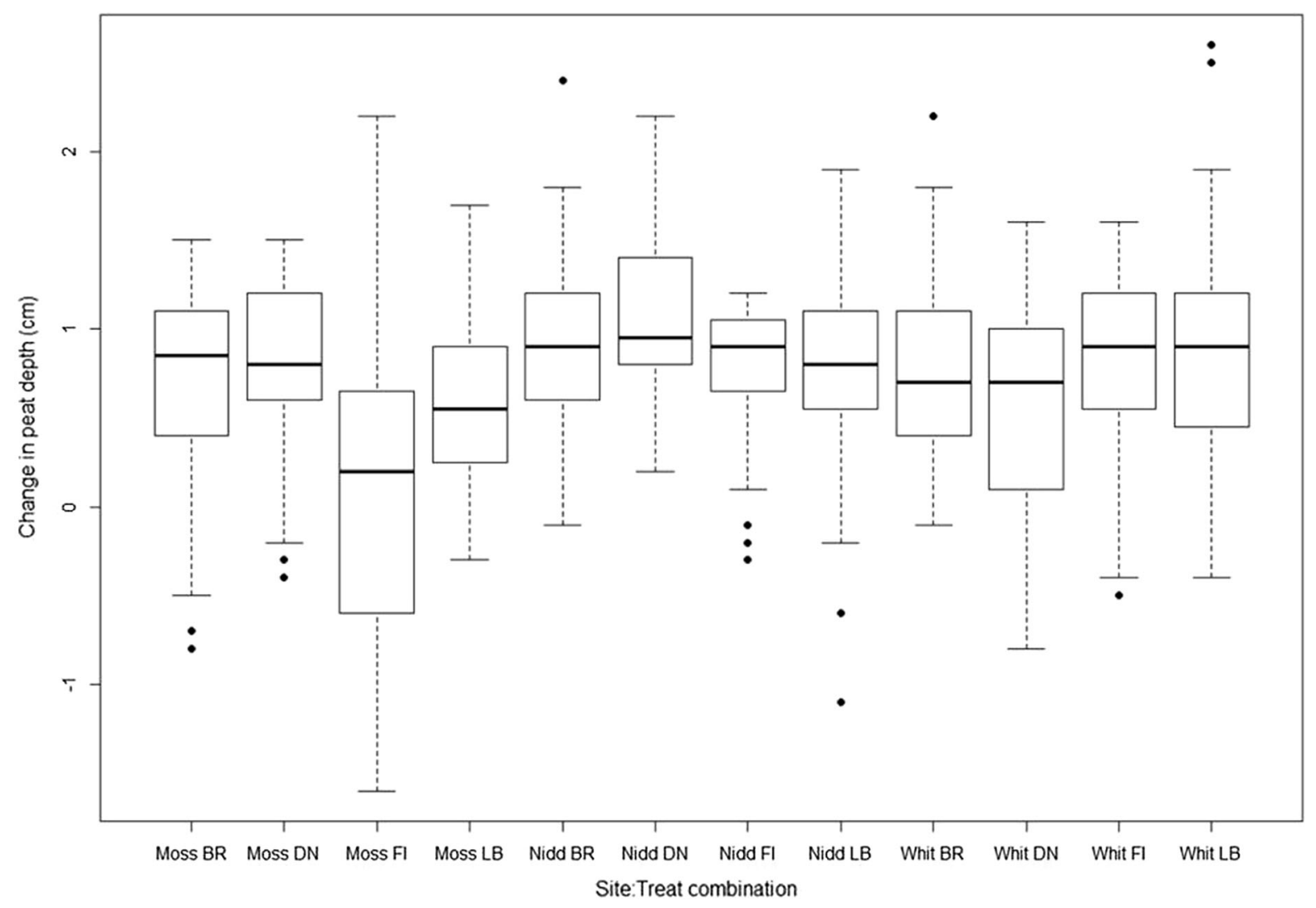

Fig. 5 Shrinkage and expansion ranges of changes in peat depth (in cm compared to initial peat levels) measured in the field under naturally fluctuating water tables for different managements at Mossdale (Moss), Nidderdale (Nidd) and Whitendale (Whit) between August 2014 and December 2015.

in WTD did not interact with any other factor used in the analysis in either dataset. For the plot data, there was a significant effect of management on change in peat height $\left(\mathrm{F}_{3,410}=4.76, \mathrm{p}=0.0028\right)$ and a significant interaction between site and management $\left(\mathrm{F}_{6,410}=6.82, \mathrm{p}<0.0001\right)$. Overall, the change in peat height on burnt plots was significantly more negative (i.e. the peat either shrunk more or did not expand as much; $\mathrm{p}<0.0001$ ) than on plots under other managements (Fig. 5). However, the interaction between site and management showed that this was only the case for burnt plots at Mossdale ( $\mathrm{p}<0.05$ for all). For the +90 data, apart from considerable changes over time (Fig. 7a), the vegetation type had a significant effect on the change in peat height $\left(F_{4,167}=2.97, p=0.0210\right)$, although only peat height between Calluna-covered ground and burnt Calluna ground was significantly different $(\mathrm{p}<0.02)$ (Figs. 6,
Management codes were DN (uncut), BR (brash removed), LB (left brash) and FI (burnt). $\mathrm{N}=4$ per site for DN and FI plots; $\mathrm{n}=8$ per site for BR and LB plots. Thick lines indicate medians, boxes show the interquartile ranges and points more than 1.5 times the interquartile range are shown as dots

7b). The slope category also significantly affected the change in peat height $\left(\mathrm{F}_{1,168}=5.55, \mathrm{p}=0.0197\right)$, with steeper actual slopes (x) causing increased depth changes (y) as evident in the fitted exponential relationship across all Mossdale peat depth data of $y=122.55 * e^{-0.045 x}\left(R^{2}=0.43\right)$.

Further measurements on the permanent plots in 2018 revealed much greater shrinkage potential (Fig. 8) after an exceptional and extended dry period; notably this effect was least pronounced at the most heavily modified site (i.e. generally drier and less Sphagnum rich) and most pronounced at the least modified (i.e. generally wetter and more Sphagnum rich) site in the order Nidderdale to Whitendale to Mossdale, respectively (cf. Heinemeyer et al. 2019). 


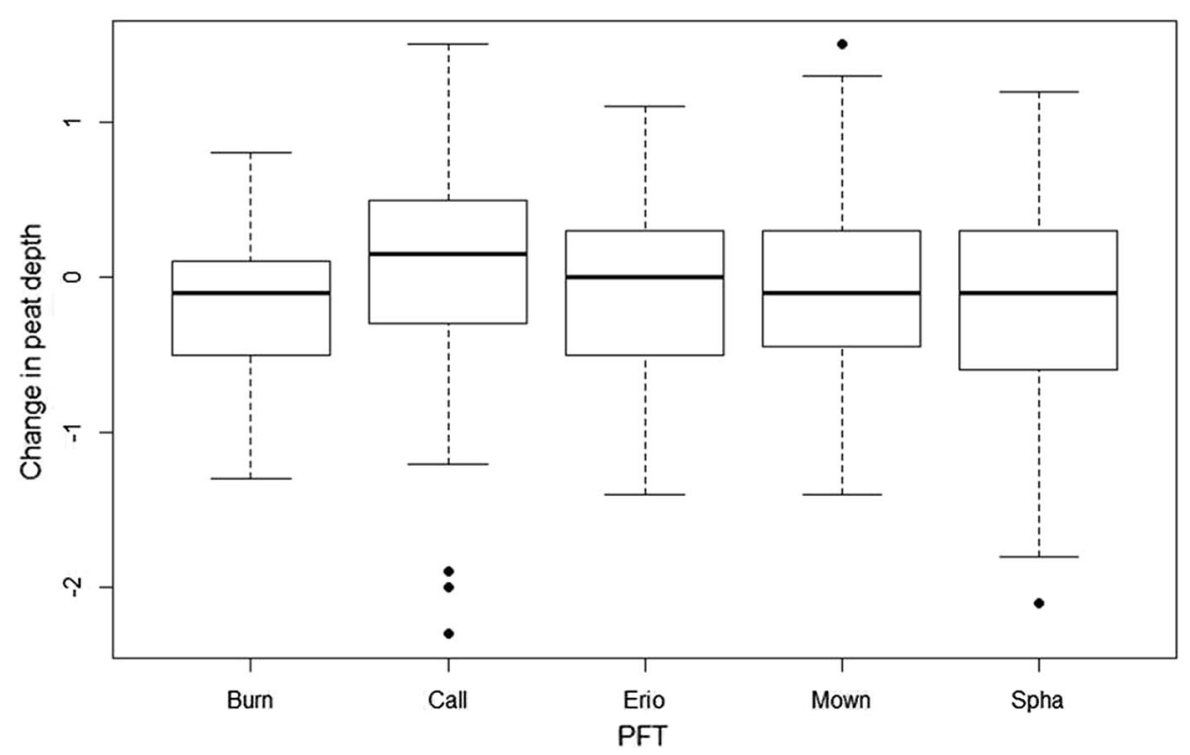

Fig. 6 Shrinkage and expansion ranges of change in peat depth (in $\mathrm{cm}$ compared to initial peat levels) measured in the field under naturally fluctuating water tables for the additional plots at Mossdale under different management and plant functional type (PFT) for burnt Calluna (Burn), mown Calluna (Mown),

\section{Discussion}

Peat shrinkage and expansion rates of several centimetres have been reported previously, mainly in connection to 'artificial' subsidence in drained peatlands, as highlighted in general by Camporese et al. (2006) and in the UK by Ramchunder et al. (2009), but also for unmanaged natural peatlands (Reeve et al. 2013). However, these data are the first to report on UK blanket bog peat depth changes in relation to seasonal WTD fluctuations, vegetation type and management, with a direct comparison to controlled conditions. The incubation study revealed important eco-hydrological differences between vegetation types (Fig. 2). After the first prolonged dry period (TP2), recovery was generally limited but Sphagnum topped cores recovered best with lower recovery observed for Calluna- and Eriophorum-topped cores. Again in the shorter second dry period (TP3), although Calluna cores showed the fastest shrinkage and had quick recovery, Eriophorum and Sphagnum cores shrunk less and only Sphagnum cores recovered fully. This difference in shrinkage and recovery highlights the eco-hydrological potential and importance of Sphagnum moss, which is of equal importance to restoration projects (i.e. Sphagnum reintroduction) unmanaged Calluna (Call), Eriophorum (Erio) and Sphagnum (Spha) dominated areas ( $\mathrm{n}=18$ for each) between August 2014 and December 2015. Thick lines indicate medians, boxes show the interquartile ranges and points more than 1.5 times the interquartile range are shown as dots

and model scenario impacts on peat hydrological functioning (i.e. Sphagnum resilience), particularly with regard to more frequent and intense summer dry periods that are predicted in response to climate change (e.g. Carroll et al. 2015).

This is also the first study to link "bog breathing" to changes in BD and thus $\mathrm{C}$ stock estimates and to consider the methodological implications. Despite the core BDs not being significantly related to WTDs overall, there was still a substantial difference between the BDs which could cause great differences if used to calculate the amount of $\mathrm{C}$ stored over large areas of peatland. On average, the $\mathrm{BD}$ of the cores maintained at a high WTD was $0.10 \mathrm{~g} \mathrm{~cm}^{-3}$ and was $0.11 \mathrm{~g} \mathrm{~cm}^{-3}$ for cores at the lower WTD (Fig. 4). Whilst the difference between these values does not appear large, the BD at a WTD of $-35 \mathrm{~cm}$ was still $10 \%$ greater than at $0 \mathrm{~cm}$ WTD. The differences between the BD taken from wetter and drier peat are even greater if each vegetation type is considered separately. BD for the dry Calluna-topped cores was $13 \%$ greater than for the wet Calluna cores and an even greater difference of $30 \%$ between the wet and dry Sphagnum-topped cores (Fig. 4). Unexpectedly, the Eriophorum-topped peat behaved differently (albeit the difference was not significant), with the drier cores actually having a BD 
Fig. 7 Shrinkage and expansion of the absolute change in peat height (in $\mathrm{cm}$ compared to initial peat levels) measured in the field between August 2014 and December 2015 under naturally fluctuating various water table depth (WTD; as absolute change from initial depth) for the additional plots at Mossdale for a the individual monitoring dates over time, and for $\mathbf{b}$ the main management and vegetation areas of burnt Calluna ground (Burnt CV), mown Calluna (Mown CV), unmanaged Calluna, Eriophorum and Sphagnum dominated areas

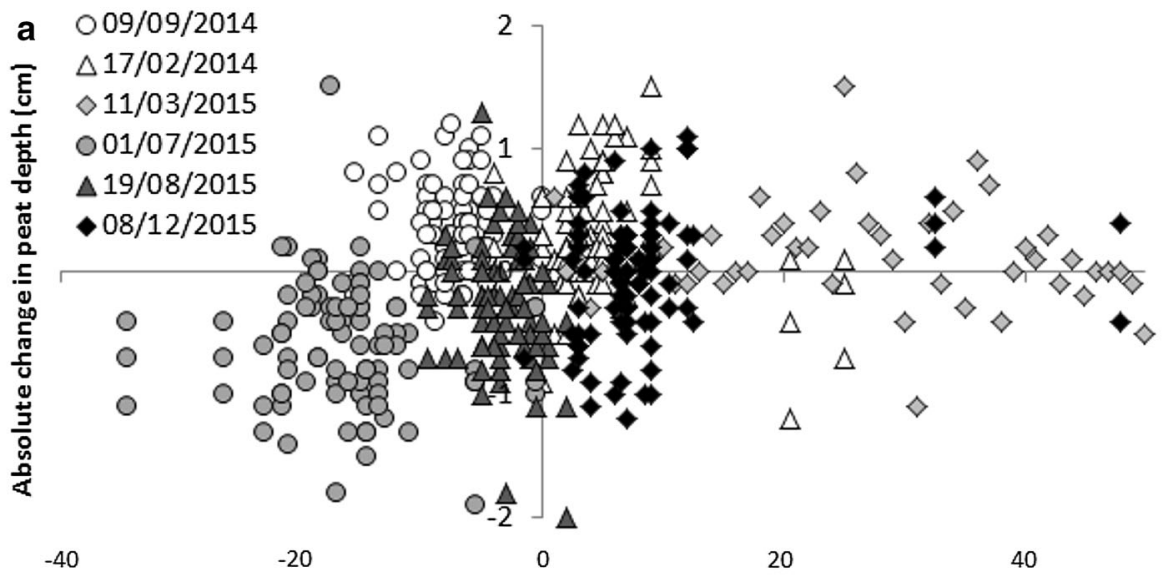

Absolute change in WTD $(\mathrm{cm})$

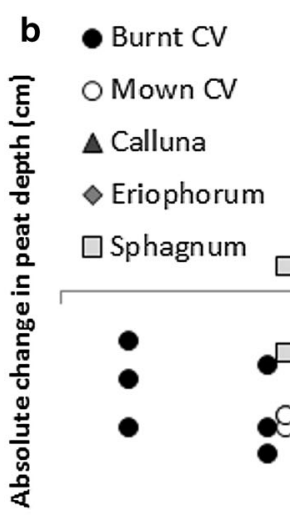

$-40$

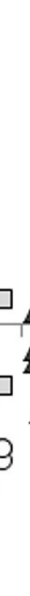

$-20$

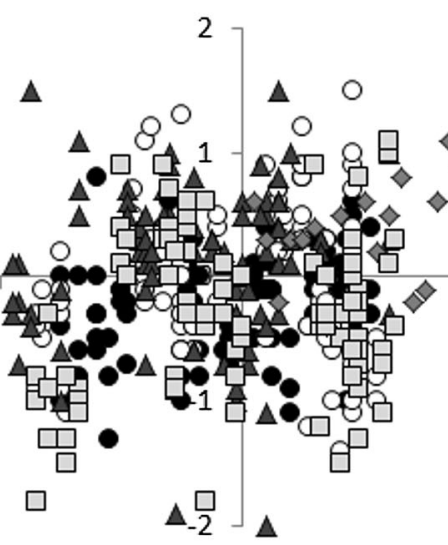

0
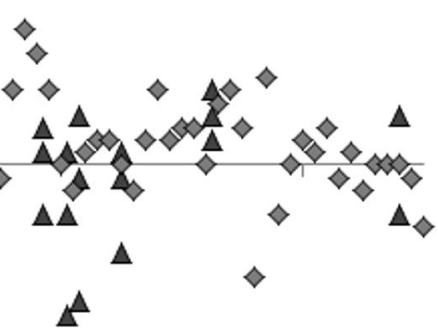

20

40 which was $23 \%$ lower than the wetter cores, which might indicate strong structural support in relation to the vertical Eriophorum roots compared to the more horizontally layered peat under Calluna plants and, particularly, Sphagnum mosses.

As the only factor causing the difference in BDs is volume of water in the peat, the percentage differences in $\mathrm{BD}$ translate directly into percentage differences in $\mathrm{C}_{\text {org }}$ for a specified volume of peat. Even if the $\mathrm{C}_{\text {org }}$ is calculated for a cubic metre of peat assuming that the $\mathrm{BD}$ of all peat above the water table is that measured in the drier cores and all peat below has the BD measured in the wetter cores, there is still a $4 \%$ difference between the $\mathrm{C}_{\text {org }}$ density of a cubic metre of peat (to $1 \mathrm{~m}$ depth assuming a dry organic matter content of $96 \%$ that has a C content of $50 \%$; these values have been estimated based on Lindsay (2010) and Heinemeyer et al. (2019)) with a WTD of $0 \mathrm{~cm}$ and a cubic metre of peat with a WTD of $-35 \mathrm{~cm}$. For Callunatopped peat, this difference is nearly 5\%, for Sphagnum topped peat, it is $13 \%$ and for Eriophorum-topped peat, it is $7 \%$ but in the opposite direction. As the seasonal differences in WTD of a typical UK blanket bog peatland ranges beyond -5 to $-40 \mathrm{~cm}$ (e.g. Moor House, see Evans et al. 1999) and WTD can be even lower on degraded and drained sites (Wilson et al. 2010), comparing the quantity of $\mathrm{C}$ stored in samples taken during wet and dry periods could easily give the impression of an "apparent" large $\mathrm{C}$ loss or gain, even if there is none.

Across both glasshouse core and field pole datasets, WTD significantly influenced the height of the peat by several centimetres, with the trend consistently demonstrating that as WTD rose (i.e. neared the surface and wetted more peat), the peat height also increased (i.e. the peat expanded). The only exception 
Fig. 8 Shrinkage and absolute change in peat height (compared to initial peat levels) measured in the field between August 2014 and March 2016 under naturally fluctuating various water table depths (WTD; as depth) and $\mathbf{b}$ including those measured in July 2018 after a prolonged dry period resulting in very low WTD on the permanent monitoring plots at the three sites Nidderdale (Nidd), Mossdale (Moss) and Whitendale (Whit). Data shown does not differentiate between the plot-level management treatments (i.e. DN, BR, LB and FI, see Fig. 5). Indicated are also the best-fit regression lines with their equations and $\mathrm{R}^{2}$ expansion depths of a the absolute change from initial
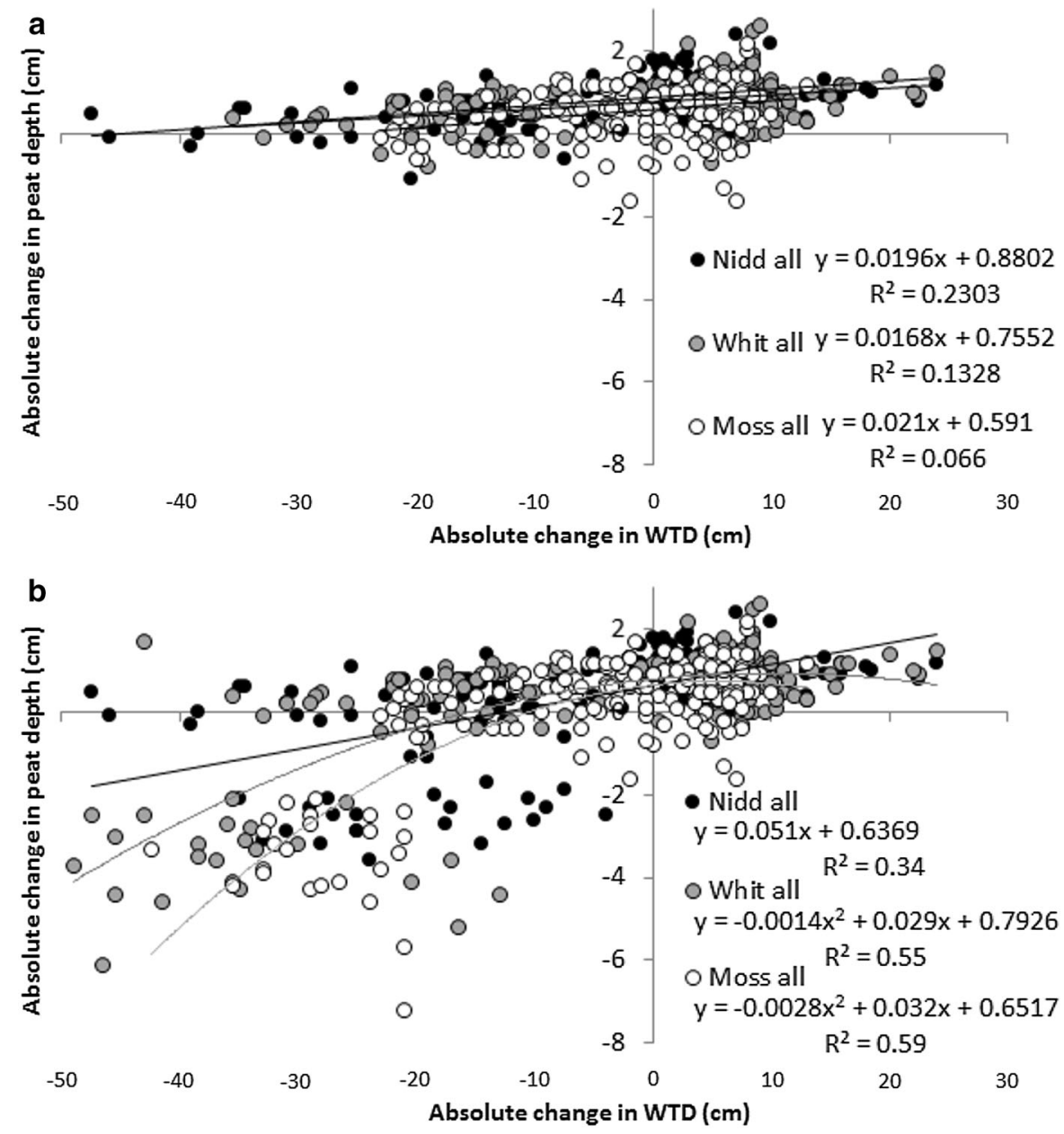

to this was measured for the poles in the +90 dataset on Calluna-dominated ground, whereby there was a slightly negative relationship between change in WTD and change in peat height. However, the WTDs recorded for this group were usually quite deep (up to $-55 \mathrm{~cm}$ ) meaning that, as this was the only group for which a change in WTD over $13 \mathrm{~cm}$ was recorded and there were 18 occasions on which this occurred, the peat was usually very dry. Therefore, as evidenced in the glasshouse cores where recovery from a deep WTD was slow and did not always happen fully (cf. Set2 in TP2 to TP3 or TP4), these Calluna-dominated areas may have shown a different relationship between peat movement and WTD from the other plots because they were often subject to very deep WTDs rather than because they were Calluna-dominated. Additionally, some of these areas were located on the steepest slopes of any included in the study, which is likely to have affected the WTD and peat height at least as much, given that this was also a significant factor.

Similarly, the significant effect of burning (FI plots) on the change in peat height (Fig. 5) may be explained or influenced by other factors; as this effect was only observed at Mossdale and these plots were in the same catchment as the Calluna-dominated plots on the steepest slope, slope could also have affected the FI plots. Additionally, even if slope did affect the peat height change on the FI plots, it is not possible to say whether burning actually caused the greater shrinkage/less expansion because the peat surface fluctuations were not measured on the same areas before burning (and, indeed, this whole area has a history of burning which may have somewhat affected the peat fluctuations under the other managements and vegetation types). 
Moreover, the additional 2018 monitoring after an extended dry period with very deep WTD revealed an emerging site difference related to generic BD differences (additional soil samples revealed that the average BD did not differ between plot management but did in the top $30 \mathrm{~cm}$ between sites, decreasing from Nidderdale $\left(0.13 \mathrm{~g} \mathrm{~cm}^{-3}\right)$ to Whitendale $\left(0.12 \mathrm{~g} \mathrm{~cm}^{-3}\right)$ to Mossdale $\left(0.09 \mathrm{~g} \mathrm{~cm}^{-3}\right)$, see Heinemeyer et al. 2019). It is important to note that shrinkage during this dry period was greatest on the least modified site and smallest on the most modified, with peat at Mossdale shrinking up to $7.2 \mathrm{~cm}$, peat at Whitendale shrinking up to $5.2 \mathrm{~cm}$ and peat at Nidderdale shrinking up to only $3.6 \mathrm{~cm}$. Therefore, ground level measurements of peat shrinkage during prolonged dry periods could potentially be used as an indicator of habitat status and degree of modification; in fact, remotely sensed "bog breathing" (e.g. using interferometric synthetic aperture radar (InSAR) data) could have real potential in contributing to large scale assessments of bog habitat status. Moreover, the change from a best fit linear to a polynomial regression fit (from the most modified to the two less modified sites, respectively) for the increase in shrinkage with declining WTDs (Fig. 8) is noteworthy and should be explored further at other sites in relation to characterising habitat condition and eco-hydrological functioning.

Overall, as expected, WTD seems to be the main driver of peat surface fluctuations, with a drop in WTD causing shrinkage of the peat. Although management may have an effect on changes in peat height, this effect is considered likely to be relatively small. Moreover, whilst vegetation type may also have effects on overall peat height in the long-term, in the short-term impacts could be more easily detectable as changes in $\mathrm{BD}$, and general $\mathrm{BD}$ differences were detected between sites in relation to habitat condition. Therefore, WTD and site condition should be taken into account when measuring BD and peat depth, especially if changes are being investigated over time and/or these measurements are used to calculate $\mathrm{C}$ densities and $\mathrm{C}$ stocks. Specifically, the dominant vegetation type should also be considered and be accounted or controlled for when choosing sampling areas for measuring BD.

Given that WTD alone was responsible for up to a $30 \%$ difference in BD of peat from the same site dominated by the same vegetation, $\mathrm{C}$ losses calculated in other studies of UK soils, such as the $2 \%$ carbon loss per year calculated by Bellamy et al. (2005) in soils with $\mathrm{C}_{\text {org }}$ content greater than $100 \mathrm{~g} \mathrm{~kg}^{-1}$, are very likely questionable. Notably, Bellamy et al. (2005) used loss on ignition to determine the organic content of their soil and multiplied it by 0.5 for the $\mathrm{C}_{\text {org }}$ content of their soil (expressed as $\mathrm{g} \mathrm{kg}^{-1}$ ). They then derived the BDs of their soils (see Table 1 in Bellamy et al. $2005)$ by using the equation $1.3-\left(0.275 \ln \left(\mathrm{C}_{\text {org }} / 10\right)\right.$, i.e. they did not measure BD, but based BD on Howard et al. (1995) although it is unclear how and from what this equation was originally derived. Additionally, some of the peaty soils surveyed underwent great changes in land use between the two survey periods, perhaps most notably a coniferous woodland which turned into upland heath in the space of 24 years, a bog which grew a deciduous wood in 20 years and an area of rough grazing which reverted to a bog (condition unknown) over 22 years (pers. comm. with G. Kirk).

Therefore, one potential explanation for their reported decline in $\mathrm{C}$ stocks may lie in the fact that Bellamy et al. (2005) estimated their BD rather than measured it. Bellamy et al. (2005) also only took cores to a depth of $15 \mathrm{~cm}$, which would almost certainly not have been to the base of the peat. Therefore, if the water table had been higher during the second set of measurements, the BD would have been lower meaning there would have been less matter-and therefore less organic matter and $\mathrm{C}_{\text {org }}$ - than in the first set of cores.

This point can be illustrated using the differences in BD under wet and dry conditions for the three vegetation types to predict potential impacts on $\mathrm{C}$ stock estimates (Fig. 9). Assuming that BD is constant over $15 \mathrm{~cm}$ depth (BD was only measured in the top $5 \mathrm{~cm}$ in the glasshouse study) as was sampled by Bellamy et al. (2005) and assuming a dry organic matter content of $96 \%$ with a $\mathrm{C}_{\text {org }}$ of $50 \%$ as above, the average difference in $\mathrm{C}_{\text {org }}$ content between wet and dry cores taken across a mixture of vegetation types is $10.8 \%$, with the difference for Calluna-topped cores being $12.5 \%$, for Sphagnum-topped cores $30.3 \%$ and for Eriophorum-topped cores - $23.7 \%$ (Fig. 9). Taking the average original $\mathrm{C}_{\mathrm{org}}$ content of $439.7 \mathrm{~g} \mathrm{~kg}^{-1-}$ from Bellamy et al.'s (2005) study for the $>300 \mathrm{~g} / \mathrm{kg}$ soils group (i.e. organic soils) and subtracting their reported $2 \%$ change per year cumulatively over 12 years (the minimum gap between samples in their study), soils would have lost $21.5 \%$ of their SOC- 


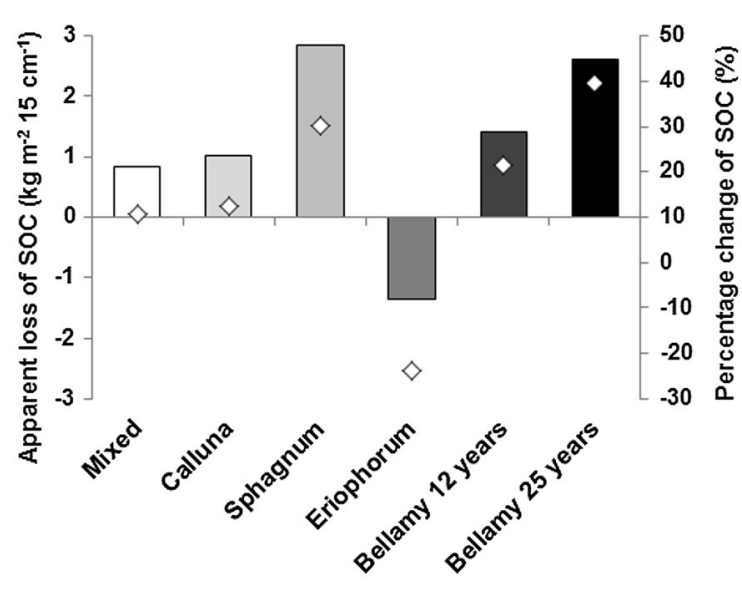

Species or years since original sample

Fig. 9 Calculated changes in soil organic carbon (SOC) stocks (bars and left-hand axis) based on changes in mean bulk densities (see Fig. 4) and calculated percentage changes (hollow diamonds and right-hand axis) between wet $(0 \mathrm{~cm}$ WTD) and dry $(-35 \mathrm{~cm}$ WTD) cores after 9 months at their respective WTDs in the laboratory trial for the different vegetation groups (Calluna, Sphagnum, Eriophorum) and an assumed equal mixture of vegetation types (Mixed) over $15 \mathrm{~cm}$ depth and the corresponding cumulative loss of SOC calculated over 12 and 25 years based on the reported $2 \%$ annual $\mathrm{C}$ loss estimates by Bellamy et al. (2005) for organic soils (see main text for details)

assuming a constant BD between sampling of $0.10 \mathrm{~g} \mathrm{~cm}^{-3}$ (the average BD measured in this study). This gives a value equivalent to $1.42 \mathrm{~kg} \mathrm{C} \mathrm{m}^{-2}$ over a depth of $15 \mathrm{~cm}$. Over a period of 25 years (the maximum sampling gap in their study), soils would have lost $39.7 \%$ of their $\mathrm{C}$, a value equivalent to $2.62 \mathrm{~kg} \mathrm{C} \mathrm{m}^{-2}$ over $15 \mathrm{~cm}$. The apparent change in $\mathrm{C}$ stocks between wet and dry BD for the Sphagnum dominated peat cores was $2.85 \mathrm{~kg} \mathrm{C} \mathrm{m}^{-2}$ over $15 \mathrm{~cm}$ (Fig. 9), which is even higher than the maximum $\mathrm{C}$ loss for the data reported in Bellamy et al. (2005).

Therefore, based on the drought-induced changes in $\mathrm{BD}$ from the laboratory cores, the reported change in soil C stocks in Bellamy et al. (2005) is well within the calculated "apparent" changes based purely on possible seasonal peat shrinkage and expansion. The BD measurements in this study were taken from a relatively narrow range (albeit over an extended period) of WTD of $0 \mathrm{~cm}$ and $35 \mathrm{~cm}$, whilst the range of WTDs in the sampling programme of Bellamy et al. (2005) might have been even greater, reflecting not only changes in climatic conditions but also management. It is also possible to estimate the change in peat depth implied by Bellamy et al. (2005). Taking the original C content of $439.7 \mathrm{~g} \mathrm{~kg}^{-1}$ soil and using Bellamy et al.'s (2005) reported 2\% annual C loss from soils with $\mathrm{C}_{\text {org }}$ content of greater than $100 \mathrm{~g} \mathrm{~kg}^{-1}$, this corresponds to a "loss" of $\sim 0.3 \mathrm{~cm}$ in the first year. Using the SOC percentage losses calculated above, this gives a "loss" of $3.2 \mathrm{~cm}$ over 12 years and $6.0 \mathrm{~cm}$ over 25 years. The former is well within the changes in peat depth observed here (Figs. 3, 5) purely by usual fluctuations in peat shrinkage and expansion (most likely in relation to WTD changes), the latter also when under extreme drought (Fig. 8).

\section{Conclusions}

The laboratory and field comparisons reported here supported the two initial hypotheses: firstly, that 'apparent' changes in $\mathrm{C}_{\text {org }}$ densities can be explained by peat surface fluctuations, therefore highlighting the need to consider BD changes when reporting $\mathrm{C}$ stocks; secondly, that peat surface and BD fluctuations can be affected by land management, vegetation type and WTD. Moreover, the differences in recovery rates after shrinkage due to drought between vegetation types highlight the crucial role Sphagnum has in creating a more drought resilient peat matrix, with important implications for restoration work at degraded sites with low or no cover of Sphagnum moss. In terms of BD, our study only focused on its impacts in the surface peat layer, since the top $5 \mathrm{~cm}$ are probably most greatly impacted by changes in WTD; therefore, future research should assess vertical BD changes in order to capture a more detailed impact on $\mathrm{C}$ stock assessments.

Importantly, the final dataset in 2018 after a prolonged drought period across much of the UK and Europe, revealed more pronounced "bog breathing" responses between the three sites. This difference in shrinkage response related to generic differences in sites' BDs across a spectrum of less to more modified blanket bog habitat, which could function as a possible indicator of bog condition, as shown recently by Howie and Hebda (2018) for a Canadian bog. Potentially such habitat characterisation based on detecting the extent of "bog breathing" under similar climatic conditions is even detectable from space using readily available satellite radar (e.g. InSAR), which could be 
used to guide identification of degraded sites and subsequent restoration work (Stoneman and Brooks 1997).

Finally, the installed peat rods offer an exceptional long-term platform for monitoring actual peat growth across three sites in Northern England. This simple tool will allow monitoring by a lay person, such as a local farmer or gamekeeper, to enable attainment of practitioner-relevant information on the state of the peatland (i.e. ability to recover from drought conditions and net peat growth rates over time). However, we acknowledge that simultaneous measurement of BD would be necessary periodically across a range of WTDs if peat growth rates in terms of $\mathrm{C}$ accumulation were required (as opposed to growth rates in height only) and that BD measurements would not be as easy for a lay recorder to determine. Information on peat depth and changes over time is an essential component of carbon accumulation calculations (Gorham 1991) and is also used in developing carbon inventories (Parry and Charman 2013). Maintaining such sites would allow the first assessment of a long-term landscape-scale impact of different peatland management approaches, as well as climate impacts, on actual peat accumulation rates in the UK in relation to a fixed datum. Such data will be invaluable for any development, as done by Smyth et al. (2015), or validation of future carbon stock change assessments (e.g. Bellamy et al. 2005) and offsetting schemes, such as the IUCN UK's Peatland Code. Moreover, extreme shrinkage events could lead to irreversible changes in the peat pore volume and hydraulic conductivity of peat (Camporese et al. 2006), and such long-term monitoring could help identify such important changes in hydrological function in relation to bog habitat condition (Stoneman and Brooks 1997).

Acknowledgements This main part of the work has been funded by Defra (BD5104) including the PhD funding for P. Morton with further contributions from Natural England and the Moorland Association towards the writing of the thesis. Additional funding for the final 2018 data was provided from a joint collaboration between the Moorland Association, Yorkshire Water Services, United Utilities, the British Association for Shooting and Conservation and the Yorkshire Peat Partnership as part of the Yorkshire Wildlife Trust. We also acknowledge access to the three peatland sites granted by the landowners and supported by the gamekeepers. We thank Tom Sloan at the University of York (UK) who assisted with the bulk density and carbon content analysis and Anthony Jones with peat level measurements. Finally, thanks to Natural England staff (David Glaves, Iain Diack and Alistair Crowle) for comments on a draft manuscript.

Funding This main part of the work has been funded by Defra (BD5104) including the PhD funding for P. Morton with further contributions from Natural England and the Moorland Association towards the writing of the thesis. Additional funding for the final 2018 data was provided from a joint collaboration between the Moorland Association, Yorkshire Water Services, United Utilities, the British Association for Shooting and Conservation and the Yorkshire Peat Partnership as part of the Yorkshire Wildlife Trust.

\section{Compliance with ethical standards}

Conflict of interest There are no conflicts of interest.

Open Access This article is distributed under the terms of the Creative Commons Attribution 4.0 International License (http:// creativecommons.org/licenses/by/4.0/), which permits unrestricted use, distribution, and reproduction in any medium, provided you give appropriate credit to the original author(s) and the source, provide a link to the Creative Commons license, and indicate if changes were made.

\section{References}

Bain C, Bonn A, Stoneman R, Chapman S, Coupar A, Evans M, Gearey B, Howat M, Joosten H, Keenleyside C, Labadz J, Lindsay R, Littlewood N, Lunt P, Miller CJ, Moxey A, Orr H, Reed M, Smith P, Swales V, Thompson DBA, Thompson PS, Van de Noort R, Wilson JD, Worrall F (2011) IUCN UK Commission of Inquiry on Peatlands. IUCN UK Peatland Programme, Edinburgh

Bellamy PH, Loveland PJ, Bradley RI, Lark RM, Kirk GJD (2005) Carbon losses from all soils across England and Wales 1978-2003. Nature 437:245-248

Camporese M, Ferraris S, Putti M, Salandin P, Teatini P (2006) Hydrological modeling in swelling/shrinking peat soils. Water Resour Res 42:W06420. https://doi.org/10.1029/ 2005WR004495

Carroll M, Heinemeyer A, Pearce-Higgins J, Dennis P, West C, Holden J, Wallage Z, Thomas C (2015) Hydrologicallydriven ecosystem processes determine the distribution and persistence of ecosystem-specialist predators under climate change. Nat Commun 6:7851. https://doi.org/10.1038/ ncomms 8851

Evans MG, Burt TP, Holden J, Adamson JK (1999) Runoff generation and water table fluctuations in blanket peat: evidence from UK data spanning the dry summer of 1995. J Hydrol 221:141-160

Evans CD, Bonn A, Holden J, Reed MS, Evans MG, Worrall F, Couwenberg J, Parnell M (2014) Relationships between anthropogenic pressures and ecosystem functions in UK blanket bogs: linking process understanding to ecosystem service valuation. Ecosyst Serv 9:5-19

Fox J, Weisberg S (2011) An R companion to applied regression, 2nd edn. Sage, Thousand Oaks 
Gorham E (1991) Northern peatlands: role in the carbon cycle and probable responses to climatic warming. Ecol Appl 1(2):182-195

Heinemeyer A, Croft S, Garnett MH, Gloor M, Holden J, Lomas MR, Ineson P (2010) The MILLENNIA peat cohort model: predicting past, present and future soil carbon budgets and fluxes under changing climates in peatlands. Clim Res 45:207-226

Heinemeyer A, Vallack HW, Morton PA, Pateman R, Dytham C, Ineson P, McClean C, Bristow C, Pearce-Higgins JW, Thom T (2019) Restoration of heather-dominated blanket bog vegetation on grouse moors for biodiversity, carbon storage, greenhouse gas emissions and water regulation: comparing burning to alternative mowing and uncut management. Final Report to Defra on Project BD5104, Stockholm Environment Institute at the University of York, York, UK. (Awaiting final approval by Defra)

Hothorn T, Bretz F, Westfall P (2008) Simultaneous inference in general parametric models. Biom J 50:346-363

Howard PJA, Loveland PJ, Bradley RI, Dry FT, Howard DM, Howard DC (1995) The carbon content of soil and its geographical distribution in Great Britain. Soil Use Manage 11:9-15

Howie SH, Hebda RJ (2018) Bog surface oscillation (mire breathing): a useful measure in raised bog restoration. Hydrol Process 32:1518-1530

Ingram HAP (1983) Hydrology. In: Gore AJP (ed) Ecosystems of the world 4A: mires: swamp, bog, fen and moor. Elsevier, Amsterdam, pp 67-158

Kuznetsova A, Brockhoff PB, Christensen RHB (2016) lmerTest: tests in linear mixed effects models. J Stat Softw 82:13. https://doi.org/10.18637/jss.v082.i13

Lindsay RA (2010) Peatbogs and carbon: a critical synthesis. Report to RSPB Scotland. http://ww2.rspb.org.uk/Images/ Peatbogs_and_carbon_tcm9-255200.pdf. Accessed Jan 2019

Natural England (2010) England's peatlands - carbon storage and greenhouse gases. Report catalogue code NE257. http://publications.naturalengland.org.uk/publication/ 30021. Accessed Jan 2019

Natural England (2015) A strategy for the restoration of blanket bog in England: an outcomes approach. http://publications. naturalengland.org.uk/publication/5476256970702848. Accessed Jan 2019

Parish F, Sirin A, Charman D, Joosten H, Minaeva T, Silvius M (2008) Assessment on peatlands, biodiversity and climate change. Global Environment Centre and Wageningen, Wetlands International, Kuala Lumpur, p 179

Parry LE, Charman DJ (2013) Modelling soil organic carbon distribution in blanket peatlands at a landscape scale. Geoderma 211-212:75-84

R Core Team (2016) R: a language and environment for statistical computing. Version 1.1.453 2009-2018. R Foundation for Statistical Computing, Vienna, Austria

Ramchunder SJ, Brown LE, Holden J (2009) Environmental effects of drainage, drain-blocking and prescribed vegetation burning in UK upland peatlands. Prog Phys Geogr 33:49-79

Reeve AS, Glaser PH, Rosenberry DO (2013) Seasonal changes in peatland surface elevation recorded at GPS stations in the Red Lake Peatlands, northern Minnesota, USA. J Geophys Res 118:1616-1626

Smyth MA, Taylor ES, Birnie RV et al (2015) Developing Peatland carbon metrics and financial modelling to inform the pilot phase UK Peatland code. Report to Defra for Project NR0165, Crichton Carbon Centre, Dumfries

Spilke J, Piepho H-P, Hu X (2005) A Simulation Study on Tests of Hypotheses and Confidence Intervals for Fixed Effects in Mixed Models for Blocked Experiments with Missing Data. J Agric, Biol, Environ Stat 10:374-389

Stoneman R, Brooks S (1997) Conserving bogs-The management handbook. The Stationery Office, Edinburgh, p 286

Strack M, Kellner E, Waddington JM (2006) Effect of entrapped gas on peatland surface level fluctuations. Hydrol Process 20:3611-3622

Tallis JH (1998) Growth and degradation of British and Irish blanket mires. Environ Rev 6:81-122

Wilson L, Wilson J, Holden J, Johnstone I, Armstrong A, Morris M (2010) Recovery of water tables in Welsh blanket bog after drain blocking: discharge rates, time scales and the influence of local conditions. J Hydrol 391:377-386

Zuur AF, Ieno EN, Walker NJ, Saveliev AA, Smith GM (2009) Mixed effects models and extensions in ecology with R. Springer, New York

Publisher's Note Springer Nature remains neutral with regard to jurisdictional claims in published maps and institutional affiliations. 